\title{
Married Emirati Students Pursuing Teaching Careers from the Perspective of their Spouses
}

\author{
Lilly Tennant, Sumaya Saqr, and Patricia Stringer
}

\begin{abstract}
Women's enrollment in higher education in the United Arab Emirates (UAE) has increased dramatically over the years. In this paradigm of change, gender role delineation and the repercussion this has on values, thinking and priorities in life can be problematic but has been neglected in terms of research. One of the aims of the research study was to find out how spouses of female Emirati students enrolled in a Bachelor of Education teaching degree perceived the challenges their wives faced while undertaking tertiary level studies and the types of support they needed to succeed. Individual interviews with spouses were conducted and the themes discussed in this paper pertain to spouses' perception of teaching as a career for women, challenges their wives faced while undertaking higher education, and support factors contributing to degree attainment within the socio-cultural context of the UAE.
\end{abstract}

Index Terms-Married, spouses, teacher education, united arab emirates

\section{INTRODUCTION}

The United Arab Emirates is passing through a period of rapid change and transformation to evolve into a developed society with high standards of living and a secure way of life. Traditionally, the UAE society is part of the larger Arab-Moslem society characterized by close interpersonal relationships emphasizing obedience, closeness and loyalty to parents in accordance with Islamic instructions. The family, not the individual, is considered the primary unit with communal interests usually overriding individual ones. Gender role delineations and shifts have implications in orientations towards family life and family processes [1].

\section{A. The status of Women in the Changing Emirati Society}

The Emirati society, though introduced to various foreign influences, preserves its cultural and religious traditions as it adapts to changing identities. The government has made notable strides in improving several aspects of women's rights over the last few decades. Certain steps in the right direction came into effect and became obvious to the observer. Article 20, according to which women are officially permitted to include stipulations concerning the right to continue education and work in the marriage contract, is just an example of the significant assurance of women's rights [2].

Manuscript received October 5, 2013; revised December 1, 2013. The authors acknowledge the Emirates Foundation for funding this research study. Emirates Foundation for Youth and Development is an independent, philanthropic organization set up by the Government of the Emirate of Abu Dhabi to facilitate public-private funded initiatives to improve the welfare of people across the UAE.

The authors are with Emirates College for Advanced Education, Abu Dhabi, UAE (e-mail: ltennant@ecae.ac.ae, ssaqr@ecae.ac.ae, gpstring@ihug.co.nz).
The majority of Emirati women do not join the workforce for financial reasons, but more for self-satisfaction and to be active participants in the country's development [3]. H.E. Sheikha Lubna Bint Khalid Al Qasimi, the UAE Minister of Foreign Trade [4] mentioned:

Women play a vital economic role in every country in the world, including the UAE, that keeps nations like ours moving forward [...] These women, whether they are doctors or home-makers, are on the front lines of our community in transition. They are demonstrating that women have a voice, as well as a unique perspective, and a key role to play in the social and economic development of the Arab world.

The support given by the government is the one of the main reasons to where Emirati women have reached today. The Constitution of the UAE guarantees equal rights for men and women. Consequently, women enjoy the same legal status, claim to titles, access to education, employment and to health and family welfare facilities. They are also guaranteed the same access to employment, health and family welfare facilities. Women's rights to inherit property are also guaranteed and ensured [5].

\section{B. Gender Identity in the Emirati Cultural Context}

Gender roles tend to be strictly defined in the Middle East countries including the UAE. The extremity of the situation has greatly changed, particularly in terms of females found in professional positions. Nevertheless, traditional male and female roles are still noticeable throughout the Arab society [6].

From a cultural perspective, men are expected to get an education and a career, while women are raised to get married. Woman's primary role is then to bear and raise children, and this makes her role as a care-giver of greater importance than her role as an employed woman. Females are given a great deal of latitude within the family, and mothers are considerably respected and honored in the Arab culture. On the other hand, when a decision has to be made it is still supposed the duty of the male as the family's prime authority figure [7].

As reference [8] comments, "The role of the male in this society is typically that of the "breadwinner", and males are expected to provide not only for their immediate family but also for their extended family...". However, gender roles and expectations are changing with rapid social and structural changes and as women start to work more outside the home. Reference [9] note, "Despite the strong commitment to the preservation of cultural traditions, customs and values, the rapid social changes, globalization and strong presence of outside cultures inevitably affect family life processes". One example of a generational shift is an attitudinal one among younger women surrounding traditional cultural expectations 
connected to the home versus the pursuit of higher education, entering the workforce and obtaining positions in high status jobs and in key decision making positions [9].

As reference [10] notes, "Each and every person working for change in the status quo is a part of the culture within which he or she struggles. All these forces shape what is considered "right", "proper" or "natural". The drive for modernization has resulted in unintended social and gender imbalances [11].

In practice, Emirati males may agree to female members of their family working, but social requirements like gender segregation may limit work environments. This results in females preferring to be employed as teachers, predominantly because of the culturally sensitive school environment in which gender segregation and the convenient working hours enable them to enter the labor market with the consent of their families.

\section{Emirati Women's Breaking Stereotypes}

Emirati women faced many challenges before the birth of the UAE in 1971. The dominant stereotype image was of a traditionally conservative female who was prevented from fulfilling her ambitions due to the cultural factors being barriers to her advancement. However, Emirati women proved to be able to face the many challenges and thus break the barriers and achieve their goals getting what they wanted. Examples of these Emiratis are clear to the observer in all sectors. Religion, society awareness and family acceptance have been the support systems to break through and successfully participate in the development of the nation [12].

The UAE wise leadership believes that supporting women and actively encouraging their entry into previously male dominated fields is a fundamental first step towards an equal society. The UAE continues to develop women's empowerment strategies and policies to promote women, based on considerable merit, into front-line organizational positions [13].

Many young Emirati women choose to be married after graduating from high school or before graduating from university. Here, the present study sheds some light on: changing perspectives and values related to evolving cognitive, social, political aspects of life; corresponding role delineation; associated challenges; and factors supporting the married female Emirati student undertaking tertiary level studies. Although the larger part of the research study provides a much needed platform to raise and discuss issues related to challenges and support factors female married Emirati students face in pursuit of their teaching degree, this paper reports on spousal conception of teaching as a career for women, perceptions of challenges their wives confronted while undertaking higher education, and factors in support of degree attainment within the socio-cultural context of the UAE.

\section{Research Methodology}

\section{A. Design of the Study}

This exploratory study encompasses both quantitative and qualitative research methods. Data collection tools included a questionnaire, semi structured interviews, and a focus group discussion. One of the dimensions of this exploratory study was to understand perspectives of spouses of female married Emirati students in relation to: motivating factors to become a teacher, challenges faced during the course of their study and support strategies employed to complete their Bachelor of Education degree program.

\section{B. Study Participants}

As part of the larger study, participants included married female Emirati students enrolled in the B. Ed teaching degree program in an educational institution in Abu Dhabi. From an original pool of 121 married students, 102 agreed to participate and complete the questionnaire. Following the questionnaire, 30 married students and their spouses consented to be interviewed individually. For the purpose of this paper, the main study participants discussed are the spouses of married students who were pursuing a teacher education degree. Demographic information on spouses obtained from the questionnaire revealed that about $16 \%$ were between the ages of 21-24 years, over 54\% were in the age range of $25-30$ years, $30 \%$ were 30 years and above. In terms of employment, $83 \%$ were working in the public sector, $9 \%$ in the private sector, $5 \%$ were self employed and $3 \%$ were unemployed. With regards to the educational qualifications, $33 \%$ had a Bachelor's degree, 23\% had a diploma, 34\% had a high school certificate and $10 \%$ had not finished their high school.

\section{Data Collection and Analysis}

All spouses were contacted over the phone and all interviews were conducted by one of the research team members who is fluent in English and Arabic. The interview guide was prepared and the questions were based on four areas related to motivation, challenges, support factors and future possibilities. All interviews were audio recorded and transcribed verbatim in Arabic and translated into English. The Arabic and English transcripts were verified for accuracy and authenticity.

In terms of data analysis, interview transcripts were reviewed individually by each research team member. Data were coded into categories and sub-categories and through this process inter-coder reliability was obtained. Major themes were identified and are presented in the findings.

\section{FINDINGS}

The perspectives of the spouses of female Emirati students are organized into five main themes: 1) motivational factors; 2) the teaching profession 3) challenges; 3) adjustments and supports; and 4) future plans.

\section{A. Motivational Factors}

All the spouses who were interviewed mentioned that they support the importance of women's education. They believed educating women meant educating the family and the future generations. They mentioned that education is essential for further successful living. Many of them motivated their wives to study and inspired them to pursue higher education.

Every woman should have a certificate that will make her feel more secure and I am very proud of her

I am the one who encouraged her to continue her 


\section{education}

They believed that an educated mother is better able to raise her children to contribute to the overall development of their country. A few spouses mentioned that when their wives had strong feelings to drop out of the college, they encouraged and motivated them to continue by counseling them and providing physical and financial support when needed.

\section{B. Teaching Profession}

Becoming a teacher was also preferred by the majority of the spouses as the most culturally acceptable occupation as it provides their wives the opportunity to work in gender segregated environments; in other words, female only work environment.

The best job for the woman is to be a teacher.

I prefer a teaching job because I believe that she will teach generations, this is one point. The other point is the work atmosphere is suitable for her than other jobs and because of our culture, she would feel relaxed to work with females than males. This job will give her the chance to develop the children of this country and from the personal angle the school atmosphere is perfect for her, and in my opinion it is one of the best jobs.

One spouse mentioned that he asked his wife to change her course of study from pharmacology to teaching. Several were in favor of having a wife who will work and support the family. Spouses also felt that the hours involved in teaching, working in close proximity to home and the added advantage of school holidays were other aspects of the profession that were favorable.

We have three children and two have special needs so I want her to be a teacher so that she can take special care of them.

I have two sisters in education field and as a conservative family we think the teaching is the most suitable job for our ladies.

\section{Challenges}

Although spouses acknowledged the supports provided by the college, the findings from their interviews revealed that the college should have better facilities particularly a childcarelnursery and flexible options for course delivery including timing. They expressed a need for special privileges extended to married students with regards to attendance policy, maternity and flexible submission deadlines for projects.

I suggest that the college recognizes and understands students' circumstances (i.e. married, mother or has a special needs child, etc.) and deal with them accordingly.

It would be better if the system provides options; morning and evening classes, and summer courses.

.... [College] they should treat the married students with special treatment...less home work and more flexibility to attendance...

All spouses expected their wives to juggle the multiple roles of wife, mother, and daughter-in-law and college student and fulfill respective responsibilities. They acknowledged that this did create stress:
She is very busy, stressed with assignments and volunteering in activities... and she feels that she is unfair to me and our young children...

Although spouses appreciated their wives aspirations to be future teachers, issues raised indicated that the course work was too demanding, spending long hours at the college was detrimental to family life and it was difficult striking the balance between home and college. Some of them pointed out that their wives are too busy over the weekends to participate in family celebrations and events.

The college should realize that the students are also wives and mothers and they have other responsibilities...

I wish the college would consider the married students family commitments and circumstances...

When asked if they had ever thought of asking their wives to drop out of the college or quitting, the majority mentioned that they encouraged and offered support for them to continue. Only a few suggested their wives withdraw from the course as they were tired physically and psychologically. Two wanted their wives to withdraw due to pregnancy and health issues and also found that the college hours were too long and imposed pressure on the family. Despite such suggestions it is interesting to note that all female married Emirati students continued with their studies.

\section{Adjustments and Support}

All the spouses described themselves as 'supportive and empathetic' which was interpreted as showing 'commitment' or 'love'. Emotional support (listening and empathizing), building self-esteem (encouragement, expressing confidence), providing information (giving advice, gathering information), and ensuring tangible support (taking on responsibilities) were the kinds of support the spouses stated they offered. Others mentioned help with the child care duties, creating study spaces in the home, and involvement with project completion as additional ways they provided support. Several mentioned that they made adjustments in their employment duties, family and social lives in order to support their wives education. Some mentioned that they provided a housemaid to help with the children and household chores, cleaning the house, doing laundry and also with preparing meals. Data reveals that traditional values and expectations about women's roles in the home mattered and this impacted spousal behavior in terms of making adjustments and offering support.

The decision of her study was my decision, so I have to adapt to this situation, I provide her with 3 housemaids instead of one before, and all of our family member support her morally

We are living with my extended family so they help her in taking care of our kids.

Although it was clear that they respect their wives' student role, there appeared a limit to the types of duties they were prepared to undertake. For example, spouses would not prepare food or do household chores.

\section{E. Future Plans for their Wives}

Interview findings revealed that no one reported they actively discouraged or hindered the performance of their 
wives during their years of study in the B. Ed program. Indeed interview findings revealed that the majority of spouses wanted their wives to pursue further studies and/or be employed as a teacher in the public schools. Two confirmed that it was an agreed condition prior to their marriage that their wives would continue and complete their higher education degree. In terms of future plans, some spouses commented that they did not have any objections and left it to their wives to determine what they wanted to do in the future. A few direct quotes from the interviews include:

Before we got married it was her condition for me to let her continue her higher education

I encourage her to pursue her master and doctoral study It is her decision to work or to study further

Although she wanted to stop after graduation, I told her the degree will be useless if she didn't work

\section{CONCLUSION AND IMPLICATIONS}

The United Arab Emirates sets a good example of a rapid and successful development story; not only in terms of its infrastructure and economy, but also the progress of its people. The improved quality of women's education, together with the growing presence of women in the workplace, illustrates the various opportunities the country has provided for women as partners and contributors in this conspicuous nation-building process.

"Equality, social justice, ensuring safety and security and equality of opportunity for all citizens shall be the pillars of the Society." [Article 14, UAE Constitution]

The government believes in women's entitlement to full active roles in society and being active participants in the development process. This belief, which is grounded in the country's constitution, ensures the principles of universal social justice, in agreement with the teachings of Islam. Sheikh Zayed bin Sultan Al Nahyan, the UAE's founding father, once stated quite clearly that "Women have the right to work everywhere." Sheikh Zayed also stated that: "Like men, women deserve the right to occupy high positions according to their capabilities and qualifications." [14].

The growing number of Emirati women in higher education institutes is a result of increased educational opportunities and the changing cultural attitudes. Although employment is considered a male activity, several spouses interviewed in this study agreed to the future financial support provided by their wives when employed in addition to the role of a traditional housewife which the society expects. Despite their agreement to their wives working, social requirements and cultural considerations like gender segregation limit work environments and career choices for these Emirati women. Consequently, teaching is considered as a "safe" and "preferred" job. Education is, therefore, viewed as a female dominated profession. In this particular sector, the major proportion of practitioners are women, hence several opportunities do potentially exist for them to engage in career planning and to undertake leadership roles.

The results of this study also reveal that social support, family life and marital satisfaction, and spousal support and involvement were some of the many reasons that enabled these women cope and continue the learning journey. Gender roles in marriage are different as women's roles are almost always more demanding than spouses', especially for married students who encounter additional responsibilities (i.e., being wife, mother, housewife, daughter-in-law and student teacher). Hence, the need arises for educating these couples of effective coping strategies and various kinds of spousal support in addition to training of communication skills in couples to reduce stress.

Given the rapidity of change and the fact that the UAE has a youthful population, further investigation is required in the area of societal norms for males and females, their role delineation and any corresponding value contestation that may arise. In this paradigm of change, gender role delineation and the repercussion this has on values, thinking and priorities in life can be problematic but has been neglected in terms of research.

Future considerations may be in the form of providing facilities such as educational programs to empower couples (e.g., family education and stress management), increase students' self-satisfaction, and reduce life stress (e.g., flexible course schedules, course delivery mode, system (college) support, and child care facilities), and provide psychological and family consulting services at the educational institutions for the married students. Marriage counselors can also play an effective role in encouraging communication and support between these couples. The results of the present study can be applied not only to improve the students' academic standing and increase their success opportunities, but also to improve their social health and family relationships (e.g., marital and parenting quality), and functioning in daily life.

\section{APPENDIX}

Sample Interview Questions for Spouses

- What are your thoughts about your wife training to become a teacher? What motivates her to pursue this degree? What motivates you to support her?

- What adjustments have you had to make to accommodate your wife's role as a full-time student (in the home, extended family)? In what ways do you support your wife (as a husband and father)?

- Have you thought of asking your wife to drop out of college? What made you change your mind?

- How do you expect the College to support your wife as she undertakes her studies?

- What are your future plans for you and your wife after she gets this degree (employment, contribution to family finances, higher education)?

- What do you wish for your wife that she does not have as a student in this college?

- Would you like to add anything else to our discussion?

\section{REFERENCES}

[1] F. A. Simadi and M. A. Kamali, "Assessing the values structure among united Arab emirates university students," Social Behavior and Personality, vol. 32, vol. 1, pp. 19-30, 2004.

[2] S. Kelly and J. Breslin, Women's Rights in the Middle East and North Africa; Progress amid Resistance, NY: Freedom House, 2010.

[3] M. Shallal, "Job satisfaction among women in the United Arab Emirates," Journal of International Women's Studies, vol. 12, no. 3, 2011. 
[4] L. B. A. Qasimi, "Women in the mainstream," in Kamali, T.A. (Ed.), An Anthology Celebrating the Twentieth Anniversary of the Higher Colleges of Technology, Abu Dhabi: The HCT Press, 2007, pp. 33-35.

[5] Embassy of the United Arab Emirates in Washington DC. [Online]. Available: http://www.uae-embassy.org/uae/resources

[6] J. A. Ali, "Emiratisation: drawing UAE nationals into their surging economy," International Journal of Sociology and Social Policy, vol. 28, no. 10, pp. 365-379, 2008.

[7] S. Sherif, "Macroeconomic policy, localization and reducing unemployment: The crucial human resource issues for the UAE," Competitiveness Review: An International Business Journal incorporating Journal of Global Competitiveness, vol. 23, no. 2, pp. 158-164, 2013.

[8] N. Ridge, "The hidden gender gap in education in the UAE," Dubai School Government Policy Brief, no. 12, 2009.

[9] K. E. Green and D. Smith, "Change and continuity: childbirth and parenting across three generations of women in the United Arab Emirates," Child: Care, Health \& Development, vol. 33, pp. 266-274, 2006.

[10] N. A. Hegelan, "Women in the Arab World," Arab Perspectives, vol. 1, no. 7, 1980.

[11] T. J. A. Nasr, "Gulf cooperation council (GCC) women and Misyar marriage: evolution and progress in the Arabian gulf," Journal of International Women's Studies, vol. 12, no. 3, 2011.

[12] H. Itani, Y. Sidani, and I. Baalbaki, "United Arab emirates female entrepreneurs: motivations and frustrations," Equality, Diversity and Inclusion: An International Journal, vol. 30, no. 5, pp. 409-424, 2011.

[13] J. A. Ali. (2008). Structural barriers to emiratisation: Analysis and policy recommendations. Victorua University, $\mathrm{Ph}$. D Dissertation. UAE Interact, Sheikh Zayed bin Sultan Al Nahyan - A Special Tribute. [Online]. Available: www.uaeinteract.com/uaeint_misc/pdf_2005/zayed_tribute/zayed.pdf

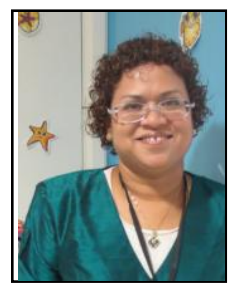

Lilly Tennant holds a Ph.D. in Special Education, University of Arizona, USA, currently working as an Associate Professor and Practicum Coordinator, Emirates College for Advanced Education in Abu Dhabi, and her expertise is in teacher education in special needs and inclusive educational practices. Areas of published scholarship, presentations and funded research include: issues in special education, use of technology in teaching and learning, parent perceptions of inclusive practices, home and school partnerships, and novice teacher development.

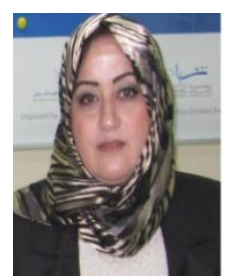

Sumaya Saqr has worked in the ELT field as a teacher, trainer and administrator for 15 years at the UAE Ministry of Education. She is currently a lecturer at Emirates College for Advanced Education in Abu Dhabi. Sumaya is a PhD candidate in Education at Curtin University, Australia.

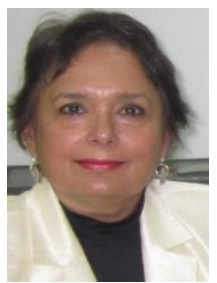

Patricia Stringer received her Education Doctorate from Massey University, New Zealand. Her professional experiences involve the following: teaching and senior management roles in primary schools; lecturing for Bachelor and Master of Educational Administration courses at Auckland and Massey universities and Ministry of Education advisory / research positions. Patricia is an educational consultant. Areas of research include: school improvement, in particular capacity building; teacher training; teacher professional development and school leadership. 